Journal Of Al Azhar University Engineering Sector

Vol. 14, No. 52, July 2019, 938-945

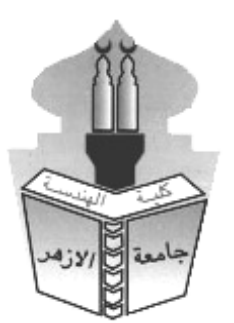

\title{
Distance Protection RELAY PERFORMANCE ENHANCEMENT THROUGH INTEGRATED CONTROL SYSTEM
}

Hassan Saad, Mohamed Mehanna, And El-Saied Osman

Electrical Engineering Department, El-Azhar University, Cairo, Egypt.

Hassan.Saad@Azhar.edu.eg, mehanna2002@hotmail.com elsaidothman@gmail.com

\begin{abstract}
Enhancement the performance of electrical power system network became essential for increasing the realiability of power transmission during any disturbance and variations. One of these variations is series compensation in heavily loaded transmission lines which affects directly the Distance Relay (DR) settings. This paper provides control system architecture to cover the setting and coordination of protection scheme based on DIgSILENT power factory program with practical representation of interactive control system by using SIMATIC manger, and WinCC programs. Applied scheme makes protection system more reliable with optimal tripping time.
\end{abstract}

Key Words: Distance Relay, SCADA, Digsilent

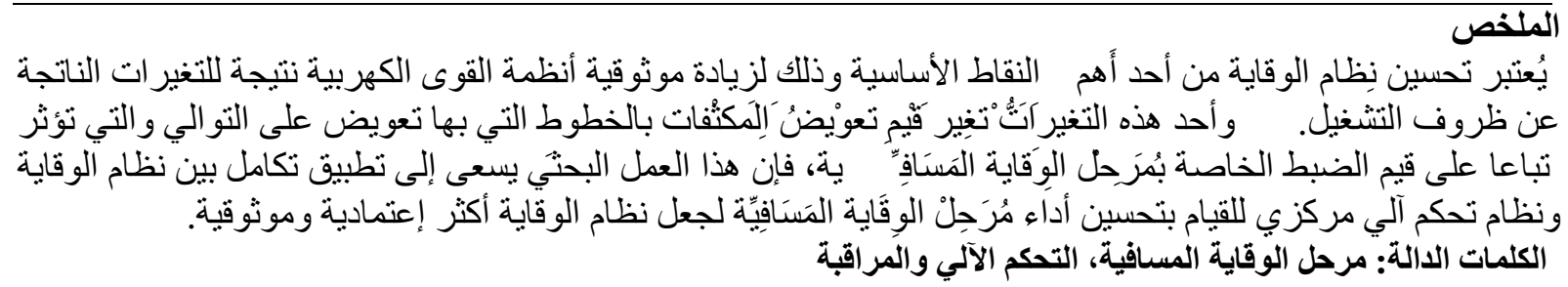

\section{INTRODUCTION}

The best protection technique achieves isolation of the fulty section quickly beside maintaining protection objectives realiability, and dependability $[1,2]$. Distance relays are one of the most important protection elements in a transmission line $[3,4]$. The reliable operation of protection systems depends on the correct design and protection settings within protective devices [5]. Series capacitor banks are frequently inserted in long power lines to reduce their total impedance, thereby permit the transmission of more power, reduce voltage drop, increase system stability limits[1], and provide better load division on parallel transmission lines. The impedance value of a series capacitor is typically (25-75) \% of the line impedance [2]. Nowadays some techniques depends on variable structure series compensation for improving voltage stability of power systems in case of emergency state as issued in [6]. To get benefit from series compensation it is necessary to overcome problems raised by series capacitor in distance protection scheme which are discussed in detail in [7].

Distance relay (DR) basically determines the line impedance by comparing the voltage and current values, if the measured impedance value of relay is smaller than the previously determined relay zone setting, then relay operates and generates trip signal $[8,9]$. Presence of series compensation operation variety in the relay path, obstructs the impedance value read by DR. An improved approach or setting the protection zone of distance relay in line with series compensation is important concern to make DRs diagnosis the fault to be correct with fast of response and minimum disturbance [2, 3, 10, and 11]. Zone impedance settings for parallel lines are determined as following: 
$\mathrm{Z} 1=\mathrm{Xline} 1 \times 85 \%$

$\mathrm{Z} 2=\mathrm{Xline} 1+\mathrm{Xline} 2 \times 20 / 2 \%$

$\mathrm{Z} 3=\mathrm{Xline} 1+\mathrm{Xline} 2 \times 20 \%$

Time setting for Zone 1 is usually set to instantaneous trip, Zone 2 protection must be time delayed by $350 \mathrm{~ms}$ so that discrimination can be achieved with the zone 1 protection on the adjacent circuit, and Zone 3 has a longer time delay than Zone 2, typically 700ms. Sometimes this zone is set to look in a reverse direction to provide backup for bus protection systems [8, $9,12]$.

In this paper scheme is made to achieve the required in two stages. Firstly, protection coordination assistance in DIgSILENT power factory program as authored program reference to $[11,14]$ is used to determine the DR settings according to selected path of the network and accordingly change in network topology. All considerations are listed and mentioned in [12], Review using an algorithms to check dynamic settings of the relay according to compensation level is given in [15]. There are articles focus on the problem of the over reach in series compensated transmission lines use [16]. A new digital distance relaying algorithm for firstzone protection for series compensated double-circuit transmission lines and a new method uses data from one end of the protected double-circuit lines to calculate the fault distance are illustrated in [17]. A proposed scheme enhances DRs performance through integrated control system, which is performed interaction between all power system network components. In brief SCADA sends correct settings to the protection device consequently with the level of series compensation. A SCADA system consists of programmable logic controllers (PLC) communicates with all protection devices and network topology status and sends/receives data with master station via a communication system [18]. The master station works as interactive control system based on DIgSILENT power factory protection coordination results and enhanced the relay performance. These results are sent to the protection devices. In consequence, accumulating between coordination setting and make it dependable on changing of the network topology or changing in line compensation steps or variable structure characteristics with considering communication network as backbone for exchange data makes system more reliable and secure to take actions and integrated with each other. To make this solution practicable for distance relaying protection, there are some requirements to be covered beside the proposed scheme. The system should have numerical relays capable to connect with communication network to send/receive all data through interactive control system proposed. Secured communication network as physical link between system devices, needs a lot of expenses versus improving system performance but it can be used for other system requirements such as automatic load sharing and applying automatic economical dispatch between stations and zones of electrical network.

2.

The sequence of evaluating work could be explained in the flow chart shown as given in Fig. 1, and the study of network model is shown in Fig. 2. It can be summarized as following: The single-line diagram shown in Fig. 2 represents a three phase, $60 \mathrm{~Hz}, 735 \mathrm{kV}$ power system, transmitting power from a power plant of $\left(6^{*} 350\right.$ MVA) generators, (1) of two winding transformer, (1) of three winding transformer, (3) of Bus bars, $(900 \mathrm{~km})$ transmission lines, each line has a series capacitor bank equals to 42.239 MVAR in case of $40 \%$ line compensation, and 330 MVAR shunt reactor on lines are similar, loads $100 \mathrm{MW}$, $250 \mathrm{MW}$. The line parameters are given in Table 1. This model is realistic power system in MATLAB/SIMULINK platform with adding parallel line between bus 1 and bus 2, and work is done with same parameters on DIgSILENT power factory program

TABLE I. LINE PARAMETERS FOR NETWORK UNDER CASE STUDY

\begin{tabular}{|c|c|c|}
\hline T.L. Parameters & Value & Unit \\
\hline R & 0.01273 & Ohm $/ \mathrm{km}$ \\
\hline L & $0.9337 \times 10^{-3}$ & Henry $/ \mathrm{km}$ \\
\hline C & $12.74 \times 10^{-9}$ & Farad $/ \mathrm{km}$ \\
\hline
\end{tabular}




\subsection{PROPOSED SCHEME}

The proposed scheme is selecting between two modes of operation, local (in this mode DR parameters is set manually where either in case of communication between control racks fail) or remotely set through SCADA. All network parameters are read such as line parameter and compensation level, then central station protection coordination assistant based on DIgSILENT program execute optimal DR settings, then go back written in DR control rack. For any variation in compensation level in network DR parameters are being updated according to interaction of SCADA system control racks.

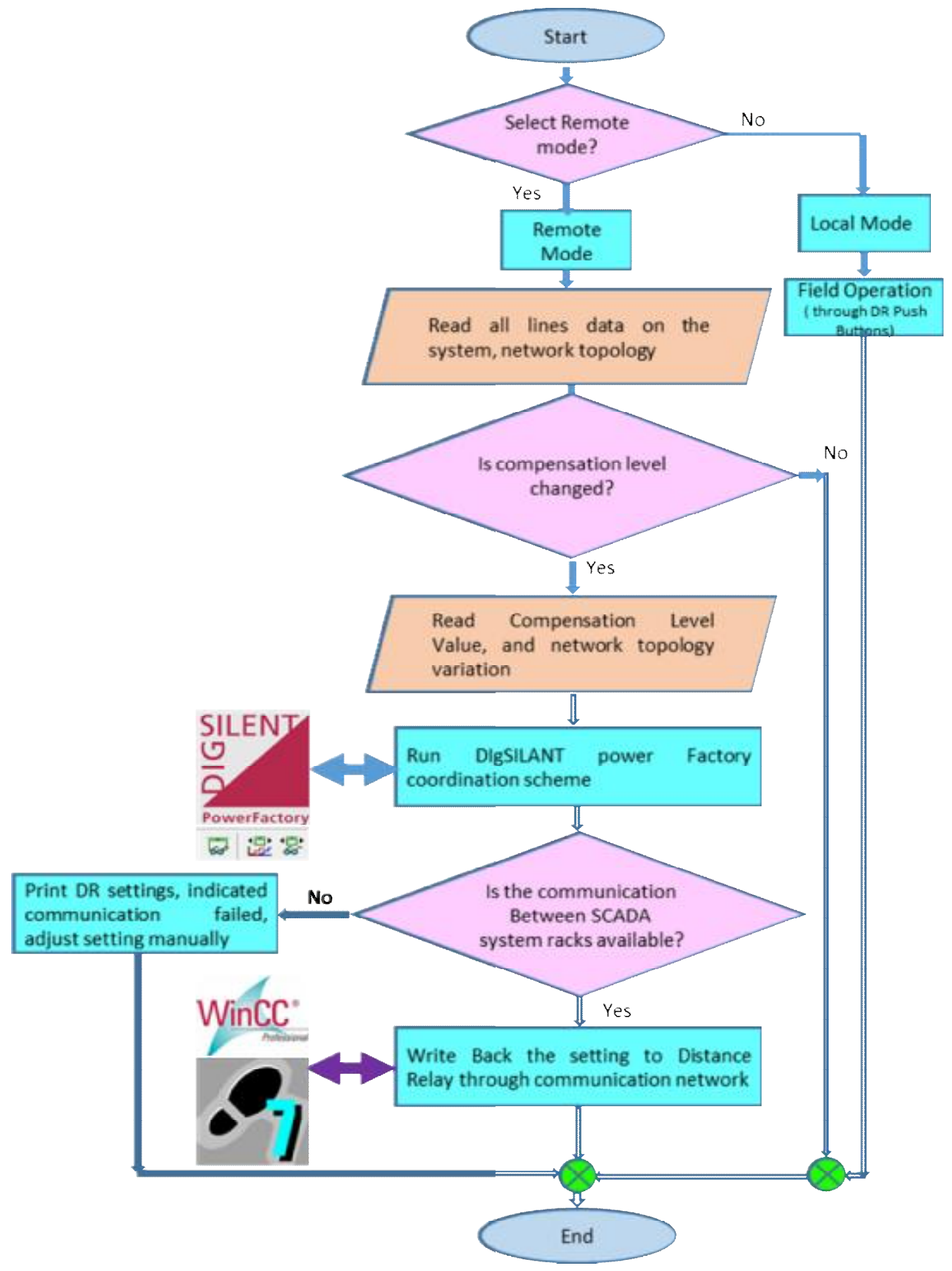

Fig. 1. Flow chart for applied sequence 


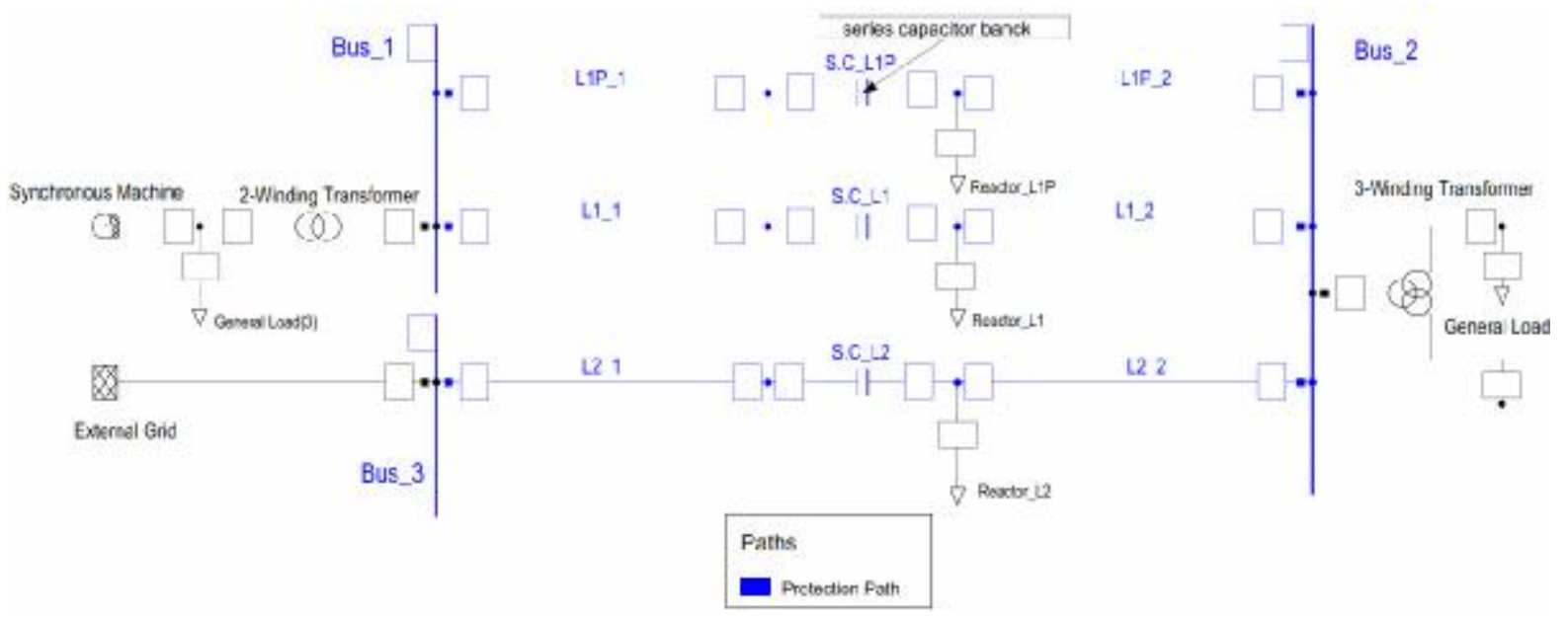

Fig. 2. Electrical network

\subsection{DISTANCE RELAY PERFORMANCE EVALUTION}

Polygon distance relays are configured on line 1_1 at bus1 as (DR1) and on line L1P_2 as (DR2), two cases are studied to illustrate the variations and their corresponding zone settings applied on protection path according to path of the selected transmission line as shown in Fig. 2. First case, Appling fault at $10 \%$ of L1P_2 then check DRs performance. Second case, appling fault at the same line location with variety of compensation without update relay settings. In section 3, same studies in practical part.

1) Case 1, in case of $0 \%$ compensation through the protected path:

- performing short circuit at $10 \%$ of the line L1P_2, tripping signal came out correctly according

- For DR1 tripping time of zone 2 which equal $0.39 \mathrm{sec}$ measuring and pick up times, since fault located in zone 2 backup protection as shown in Fig. 3. Units of axis's in ohm.

- For DR2 tripping time of zone 1 which equal $0.04 \mathrm{sec}$ measuring and pick up times, since fault located in zone one protection as shown in Fig. 4

- On the other hand, in case of setting relative to $40 \%$ compensation and the setting is not updated or the proposed scheme is not applied, all of these led to backup protection trip at $(0.04 \mathrm{sec})$ for both DRs which led to cascaded events is operated without optimal operation of DR. Figures 5 and 6 show the DR performance for DR1 and DR2 respectively.

2) Case 2, in case of $40 \%$ compensation through the protected path:

- performing short circuit at $10 \%$ of the line L1P_2 with setting updates, tripping signal came out correctly according

- For DR1 tripping time of zone 2 which equal $0.39 \mathrm{sec}$ measuring and pick up times, since fault located in zone 2 backup protection as shown in Fig. 7. Units of axis's in ohm.

- For DR2 tripping time of zone 1, which equals $0.04 \mathrm{sec}$ measuring and pick up times, since fault located in zone one protection is as shown in Fig. 8 


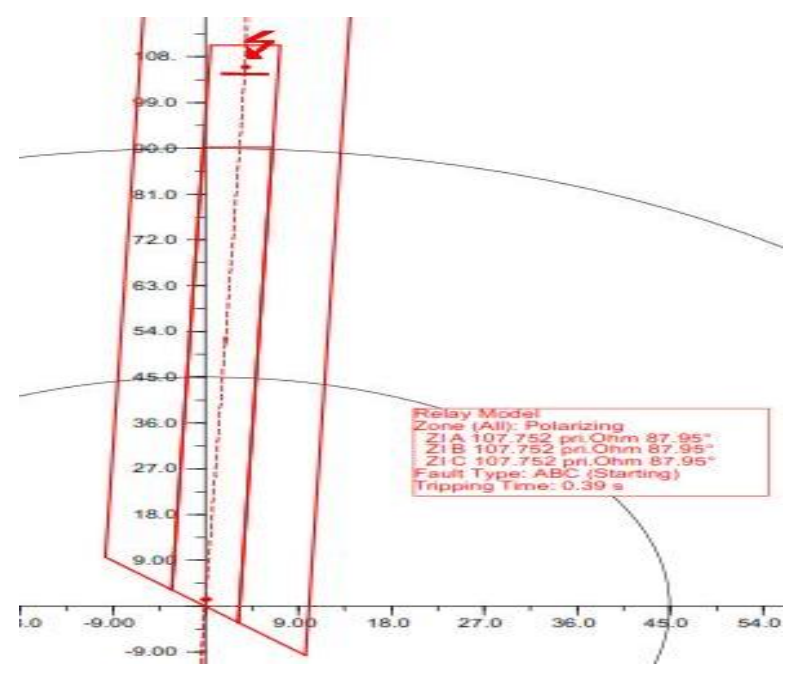

Fig. 3. R-X plot for DR 1 at $0 \%$ compensation, $0 \%$

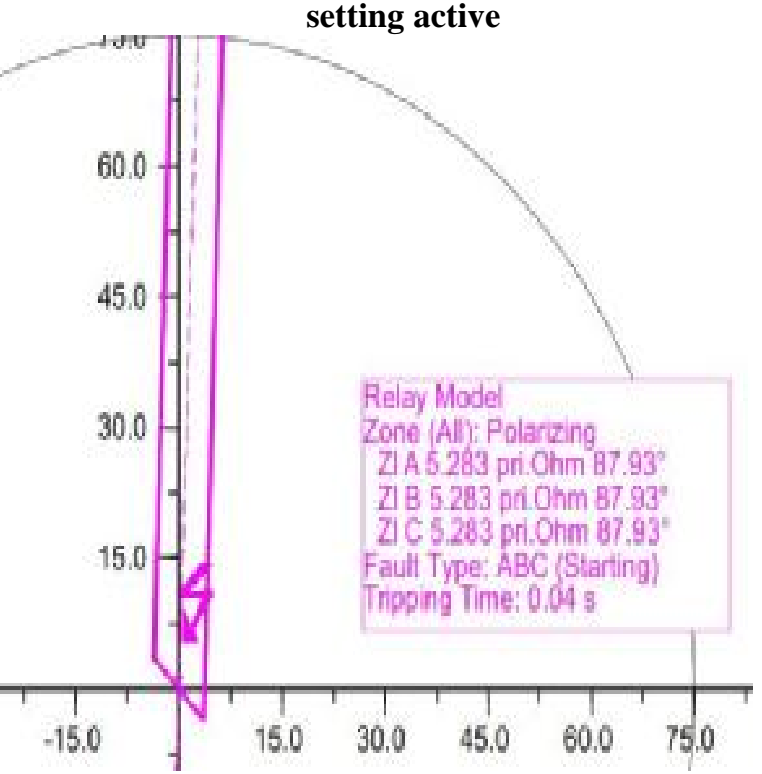

Fig. 4. R-X plot for DR 2 at $0 \%$ compensation, $0 \%$ setting active

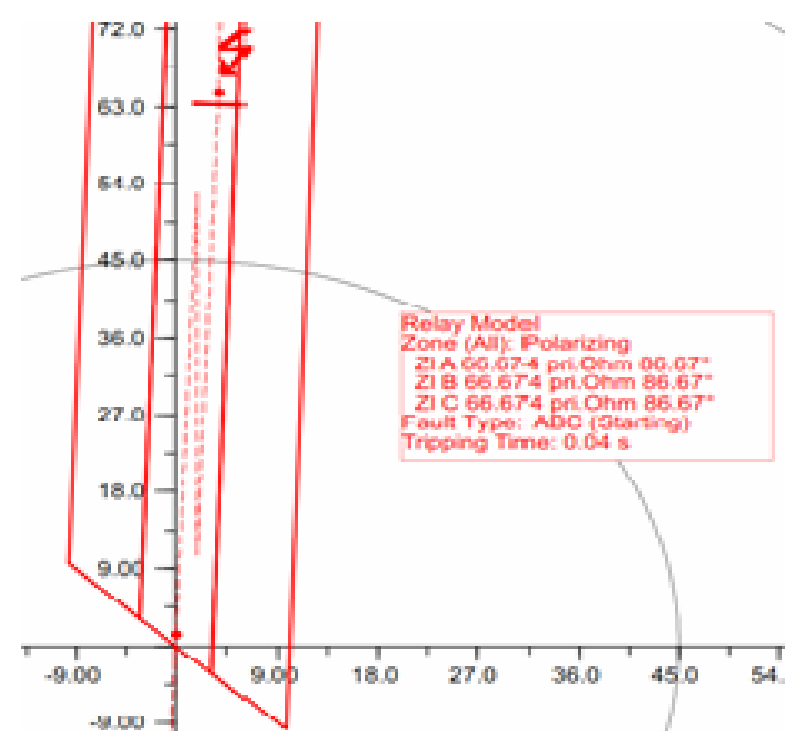

Fig. 5. R-X plot for DR 1 at $40 \%$ compensation, $0 \%$ setting active

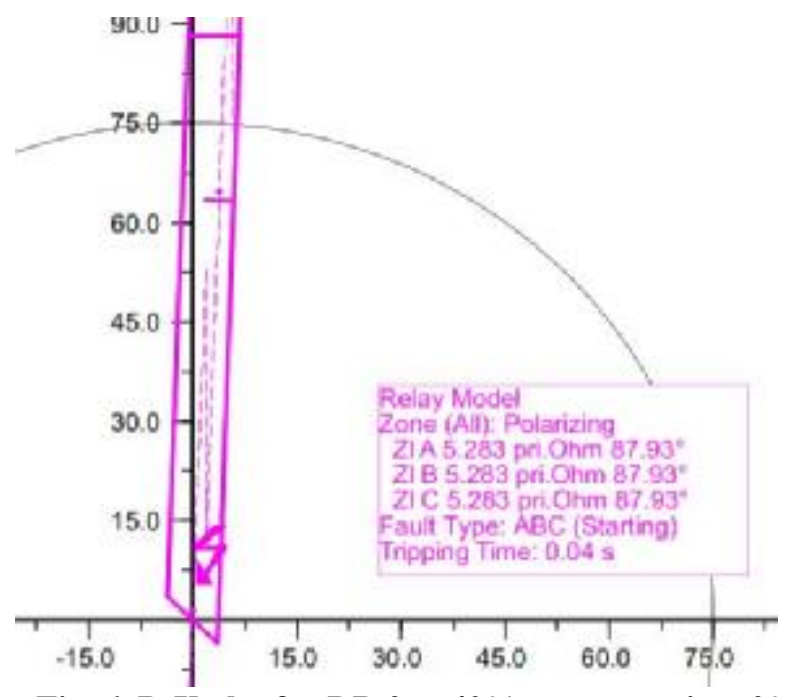

Fig. 6. R-X plot for DR 2 at $40 \%$ compensation, $0 \%$

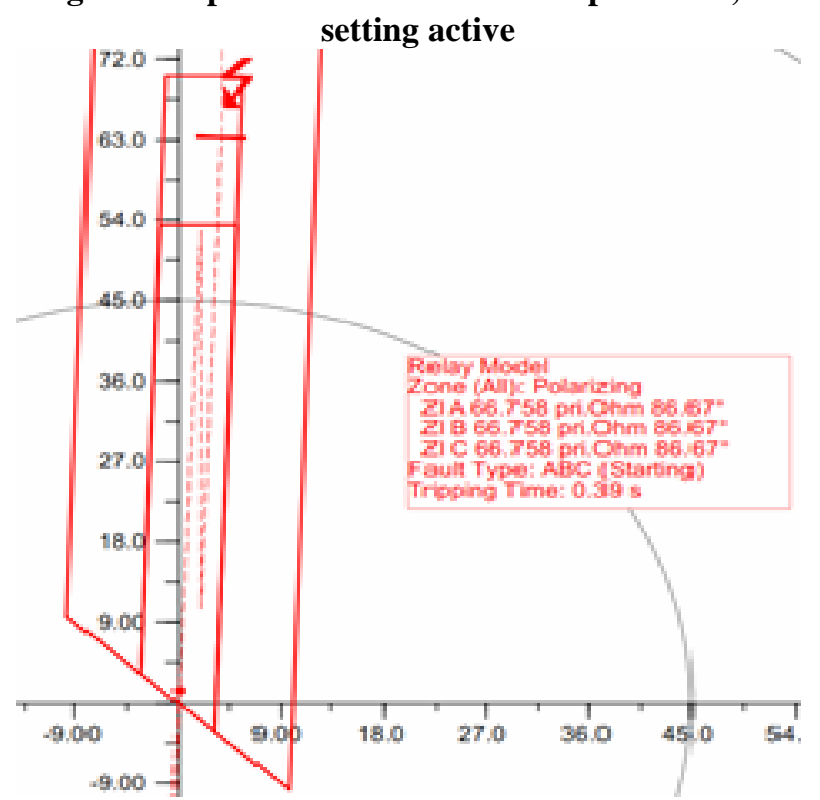

Fig. 7. R-X plot for DR 1 at $40 \%$ compensation, $40 \%$

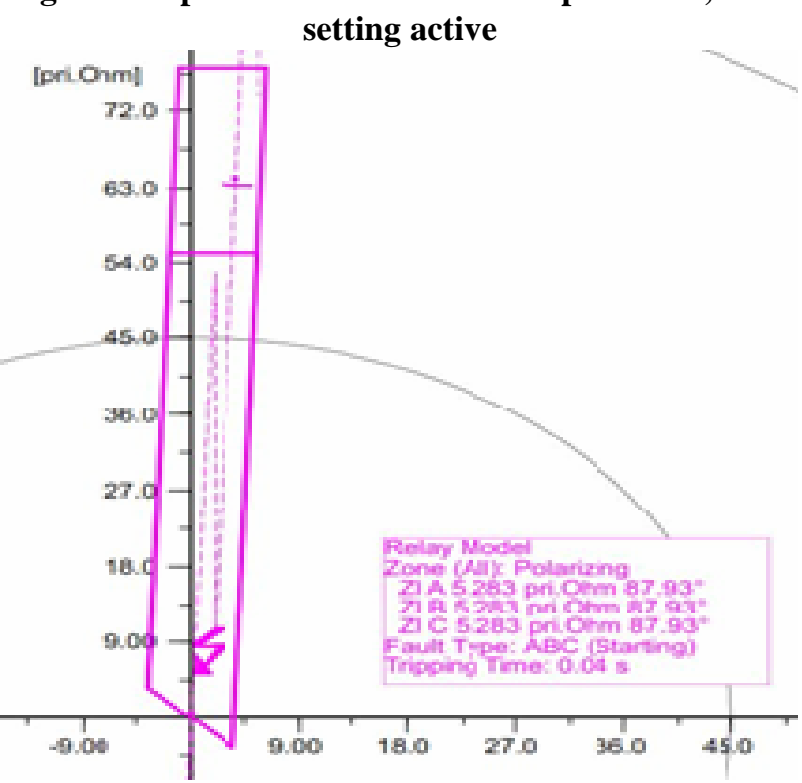

Fig. 8. R-X plot for DR 2 at $40 \%$ compensation, $\mathbf{4 0 \%}$ setting active 


\section{PROPOSED PRACTICAL SYSTEM CONFIGURATION AND RESULTS}

A practical modeling for the proposed scheme shown in Fig. 1, is represented by hardware and software packages.

\subsection{HARDWARE CONFIGURATION}

Five Programmable Logic Controllers S7_313C-2DP racks are used. Two as controllers for series compensation, two as slave DR, and one as master rack to read the DIgSILENT output coordination results, and communicates with two other Slaves DR and series compensation (S.C). A Laptop is used as server and plus programming device. NetPro communication network configuration is shown in Fig. 9.

\subsection{SOFTWARES}

PLC is programmed by SIMATIC STEP 7 V5.5 tools, SCADA station is programmed by WinCC V7.0 tools.

\subsection{PRACTICAL RESULTS VISUALIZATION}

The practical results depend on the output coordination results from DIgSILENT program which are the actual data sent by master PLC to slave (DR) according data read from slave series compensation, simulation results from WinCC actual rum time screen shown in the following figures:

- In Fig. 10, the SCADA system visualization is shown without compensation.

- DRs congruence their settings accordingly with the compensation level $40 \%$ to update DRs settings according to value, and as shown in Fig. 11

- Finally, in case of any variation occurs, the system keeps its values until any updated feedback comes from the series compensation rack as shown in Fig. 12.

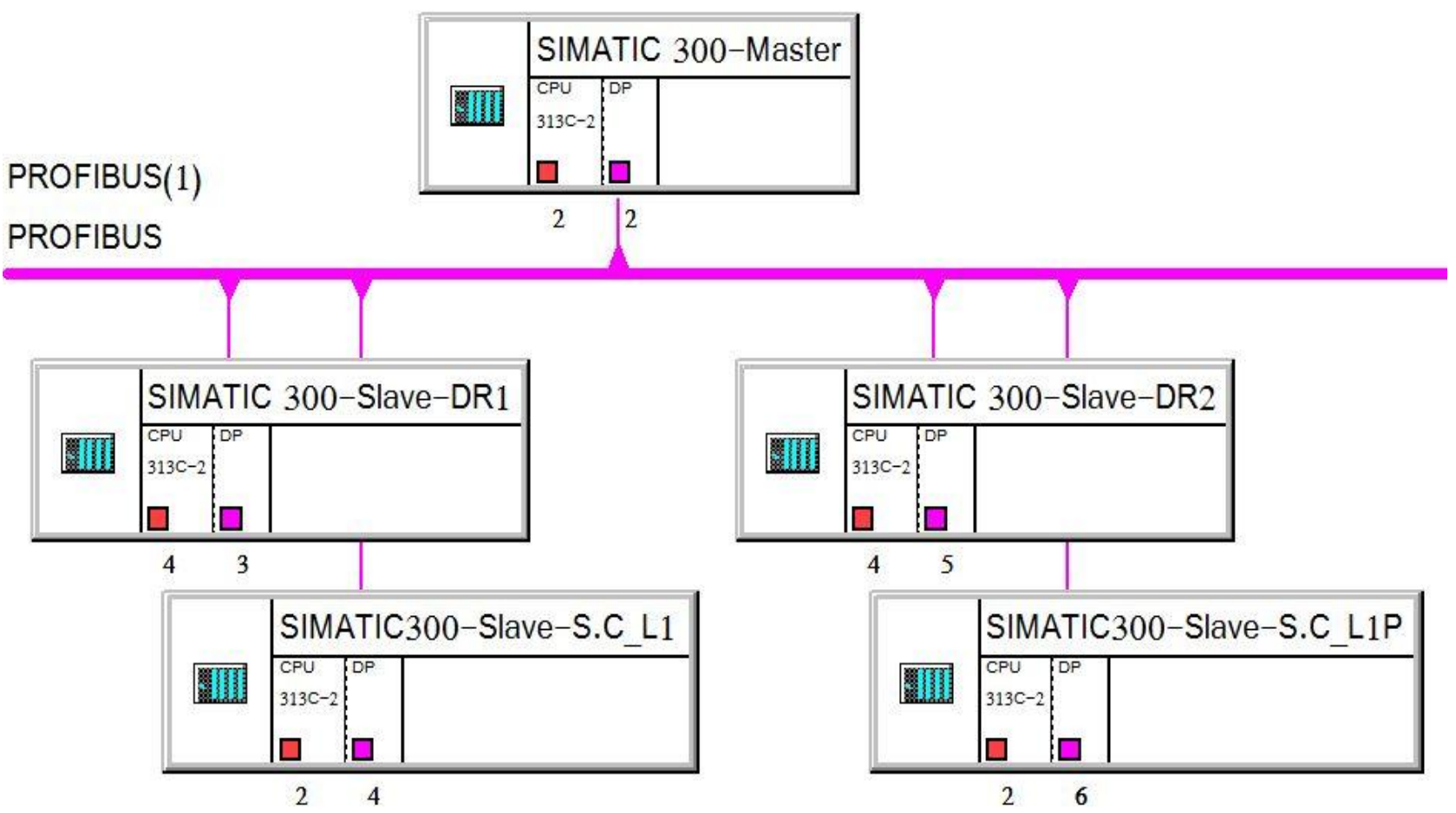

Fig. 9. SCADA hardware configuration in Step7- NetPro 


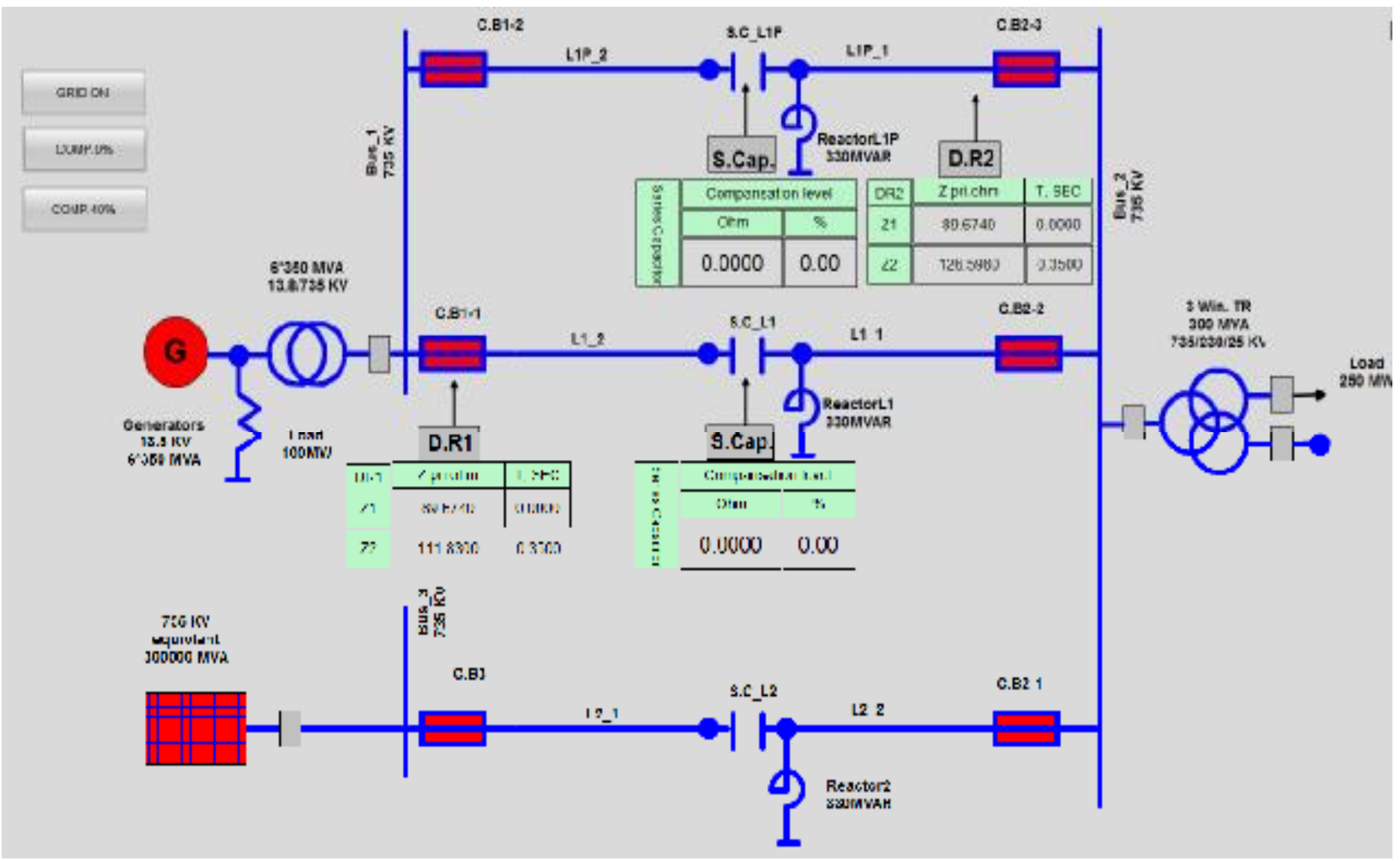

Fig. 10. Practical SCADA visualization of DRs settings at $0 \%$ compensation

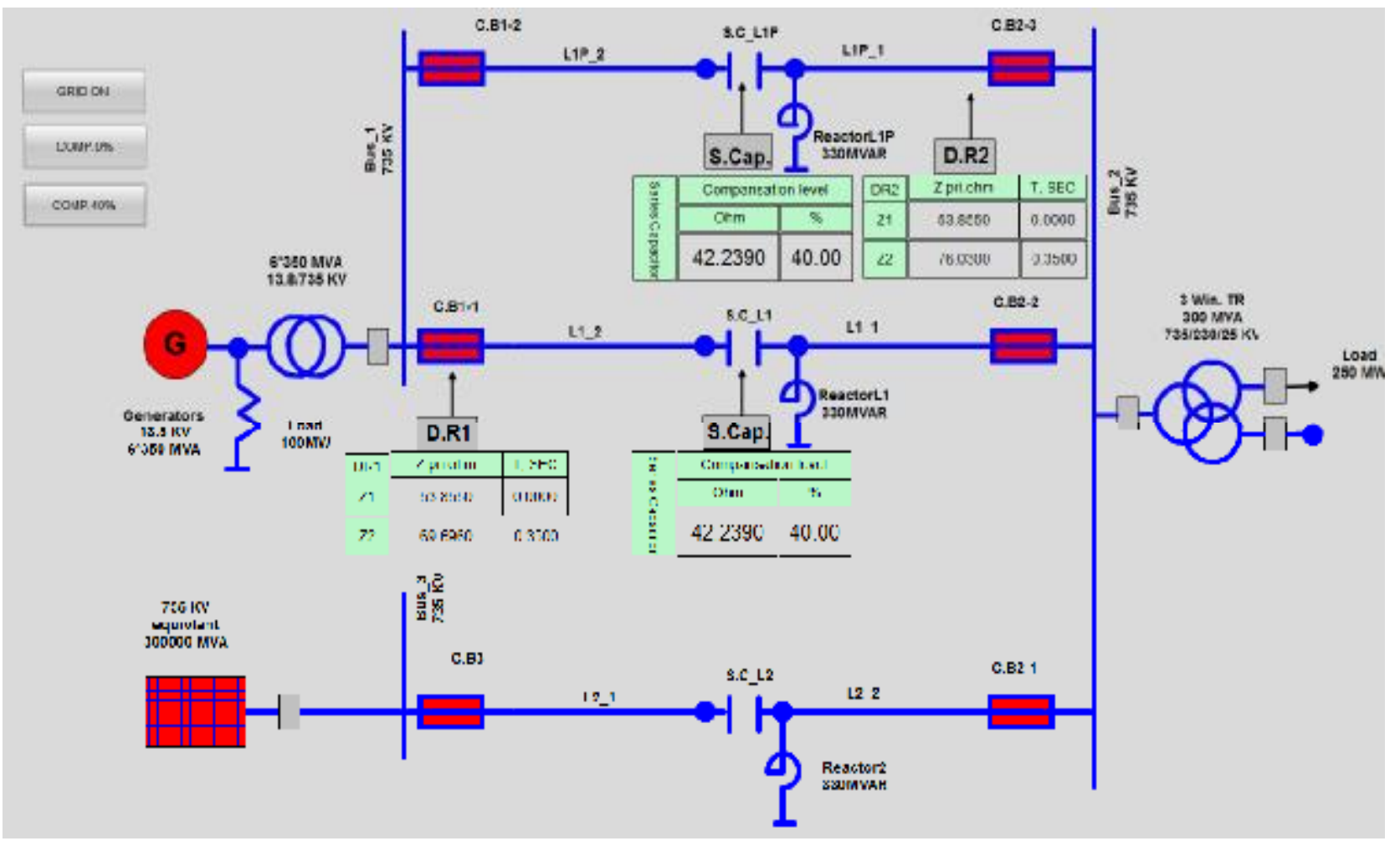

Fig. 11. Practical SCADA visualization of DRs settings at $40 \%$ compensation 


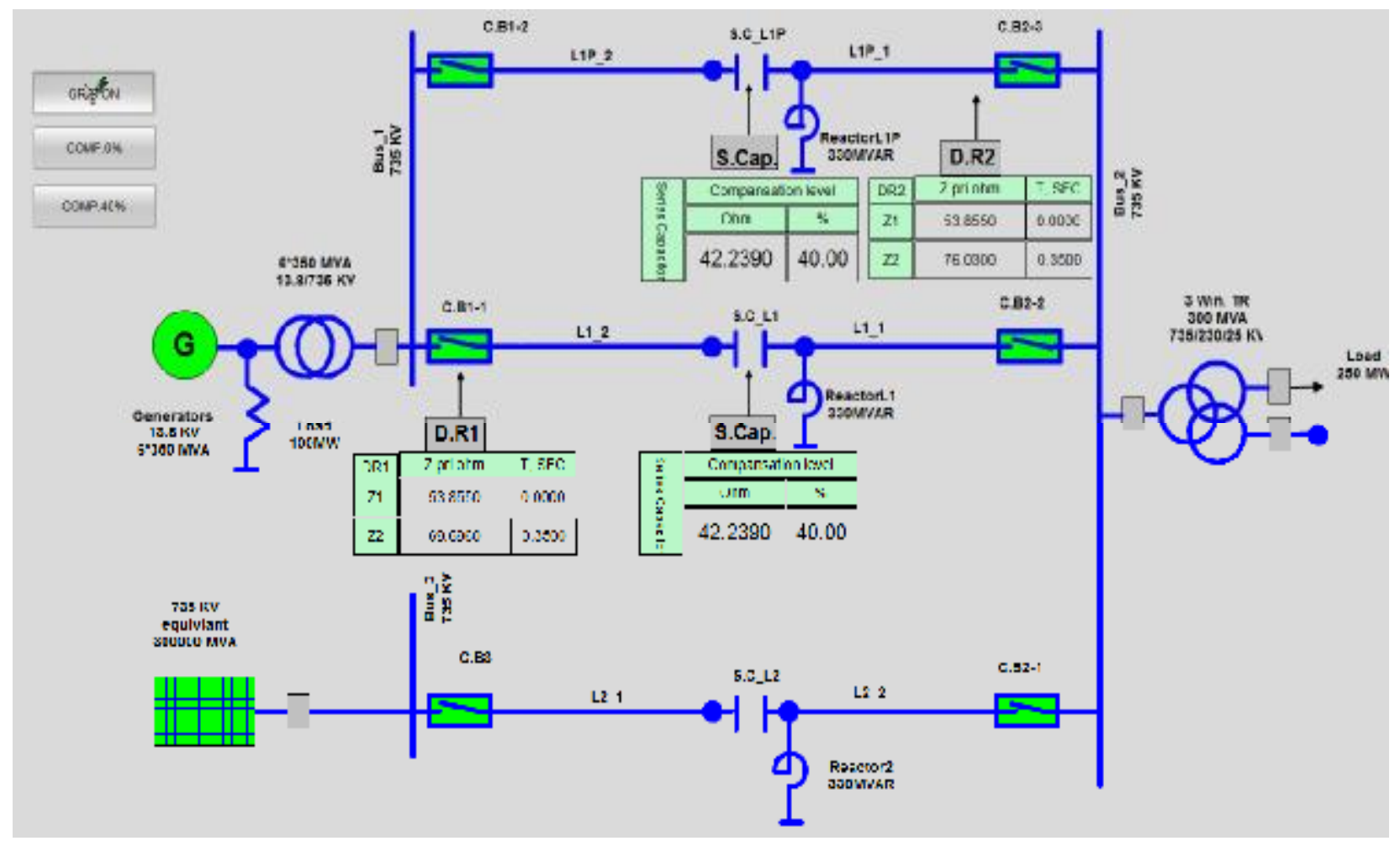

Fig. 12. Practical SCADA visualization when keep settings in case of no variation in S.C racks

\section{CONCLUSION}

Distance protection new scheme for parallel lines including also series compensated transmission lines is presented here. Update DR settings according to network changes is one of most important factors to reduce undesirable operation of the protection system. Automatic adjusting of distance relay settings through authorized program decrease mistakes made by human experience, which may led to undesirable operations.

The proposed scheme illustrates a highly activities done by integrated control system, which is used for sending data to DRs, has added many features to the protection system. One of them, makes DR operating accurately in case of series compensated transmission lines, which is as supported by results obtained in this paper.

\section{REFERENCES}

1. Blackburn J, Domin T. (2006). Protective Relaying Principle And Application. Francis: Crc Press.

2. Horowitz S, Phadke A. (2014). Power System Relaying. Usa: Wiley.

3. Jacome Y. (2009). An Example Distance Protection Application With Complicating Factors. Western Protective Relay Conference Spokane. Washington, Usa. 1-12.

4. Penthong T, Hongesombut K. (2013). An Efficient Method Of Automatic Distance Relay Settings For Transmission Line Protection. Ieee International Conference Of Ieee Region 10 (Tencon 2013). Xi'an, China. 1-4.

5. Hong Q, Booth C, Dyko A, Catterson V. (2016). Design Of An Intelligent System For Comprehensive Validation Of Protection Settings. ${ }^{13}$ th International Conference On Development In Power System Protection (Dpsp). Edinburgh, Uk. 1-7. 
6. Hemeida M A. (2008). Adaptive Variable Structure Series Compensation For Voltage Stability Improvement Using Internal Recurrence Neural Network Controller, 2008 12th International Middle-East Power System Conference. Aswan, Egypt, 1-4.

7. Kasztenny B, Brunello G. (2002). Distance Protection Of Series Compensated Lines Problems And Solutions. 2002transmission \&Distribution Latin American Conference. Sao Paolo, Brazil, 1-40.

8. Arikan O, Gursanli O, Aydin H, Yagmur E. (2016). An Algorithm For Transmission Distance Relay Setting Calculation Under Network Topology Change. Ijireeice, 4(5): 508-513.

9. Gers J, Holmes E. (2004). Protection Of Electricity Distribution Networks. Uk: Iet.

10. Yang J, Liao C, Wang Y, Chu C, Lee S, Lin Y. (2017). Design And Deployment Of Special Protection System For Kinmen Power System In Taiwan. Ieee Transactions On Industry Applications. 53(5): 4176 - 4185.

11. Jan'icek F, Martin Mucha M. (2006). Distance Digital Relay Model Developed In Atp "Foreign Model" And C++. Journal Of Electrical Engineering. 75(5): 268-275.

12. Digsilent Power Factory User Manual- Digsilent. 2014 Https://Www.Digsilent.De/En/Power-Equipment-Models.Html.

13. Ziegler. (2006). Numerical Distance Protection; Principles And Applications. Erlangen, Germany: Publicis.

14. Ieee Std. 242. (2001). Ieee Recommended Practice For Protection And Coordination Of Industrial And Comercial Power Systems. Buff Book.

15. Srivani G S, Panduranga K. (2010). Adaptive Distance Relaying Scheme In Series Compensated Transmission Lines. 2010 Joint International Conference On Power Electronics, Drives And Energy Systems \& 2010 Power India. New Delhi, India. 1-7.

16. Savalia S, Pandya V, Kumar P. (April 2016). Problem In Distance Protection For Series Compensated Transmission System. International Journal Of Engineering Research And Development (Ijerd), 1-5.

17. Kumar R, Sinha A, Choudhary K G. (2013). Computing And Communications A New Digital Distance Relaying Algorithm For First-Zone Protection For Series-Compensated Double-Circuit Transmission Lines. 2013 Third International Conference On Advances In Computing And Communications. Cochin, India, 2013, 1-5.

18. Bailey D, Wright E. (2003). Practical Electrical Network Automation And Communication System. Dutch: Elsevier. 